\title{
Chemotherapy in the Intensive Care Unit: An Evaluation of Context and Outcomes
}

\author{
Salmaan Kanji, Erica MacLean, Farah Joy Rashid, Michelle Pittman, Melanie Trinacty, David Allan, \\ and Erin Rosenberg, on behalf of the Resource Optimization Network
}

Can J Hosp Pharm. 2020;73(4):279-87

\begin{abstract}
Background: Administration of chemotherapy to highly vulnerable, critically ill patients in the intensive care unit (ICU) is becoming more common, but the process requires significantly more resources than chemotherapy administration in specialized oncology settings.

Objective: To describe the context, complications, and outcomes of chemotherapy administration for cancer-related indications in ICU patients.
\end{abstract}

Methods: For this retrospective observational study, consecutive patients receiving parenteral chemotherapy in the ICU at the General Campus of The Ottawa Hospital between January 1, 2014, and December 31, 2017, were identified using pharmacy records. The clinical characteristics of these patients, details of their chemotherapy regimens, and outcomes were analyzed.

Results: A total of 32 patients were included in the study. Of these, 27 patients (84\%) had a hematological malignancy, $16(50 \%)$ had a documented infection at the time of chemotherapy administration, and 29 (91\%) received their first cycle of chemotherapy on an urgent basis during the ICU admission rather than as a scheduled or planned treatment. Severity of illness was high both at ICU admission and at the time of chemotherapy treatment; regimen modifications, drug interactions, and adverse events were common. Remission and survival data were available for 28 patients at 12 months. Eighteen (56\%) of the 32 patients survived to hospital discharge, and $12(38 \%)$ survived to 6 months; at 12 months, survival was $25 \%$ (7 of 28 patients with available data). About one-quarter of the patients were in remission at 6 and 12 months.

Conclusion: Administering chemotherapy in the ICU is feasible, but the process is resource-intensive. Patients with aggressive hematological cancers who require treatment on an urgent basis represent the most commonly observed scenario. This study highlights the complexity of management and the importance of multidisciplinary care teams for this patient population.

Keywords: critical care, chemotherapy, cancer

\section{RÉSUMÉ}

Contexte : L'administration de chimiothérapie à des patients hautement vulnérables et gravement malades admis dans une unité de soins intensifs (USI) est de plus en plus courante, mais le processus exige beaucoup plus de ressources que dans des environnements spécialisés en oncologie.

Objectif : Décrire le contexte, les complications et les résultats de l'administration de chimiothérapie pour les indications liées au cancer de patients admis dans une USI.

Méthodes : Les patients successifs ayant participé à cette étude observationnelle rétrospective, qui recevaient une chimiothérapie parentérale dans une USI du Campus général de I'Hôpital d'Ottawa entre le $1^{\text {er }}$ janvier 2014 et le 31 décembre 2017, ont été déterminés à l'aide de dossiers de pharmacie. Les caractéristiques cliniques de ces patients, les détails de leur programme de chimiothérapie ainsi que les résultats ont fait l'objet d'une analyse.

Résultats : Trente-deux (32) patients ont été inclus dans l'étude. Parmi eux, 27 (84 \%) souffraient d'une hémopathie maligne, 16 (50\%) avaient une infection documentée au moment de l'administration de la chimiothérapie et 29 (91\%) recevaient en urgence le premier cycle de chimiothérapie pendant leur admission à I'USI plutôt que sous forme de traitement programmé ou planifié. Étant donné l'extrême gravité de la maladie lors de l'admission à I'USI et du traitement de chimiothérapie de ces patients, les modifications apportées au programme, les interactions médicamenteuses et les effets secondaires étaient fréquents. Les données relatives à la rémission et à la survie à 12 mois de 28 patients étaient disponibles. Le congé hospitalier a été donné à 18 (56\%) patients survivants sur les 32 admis et 12 (38\%) survivaient au $6^{\mathrm{e}}$ mois, alors qu'au $12^{\mathrm{e}}$ mois, le taux de survie était de $25 \%$ (7 des 28 patients dont les données étaient disponibles). Environ un quart des patients étaient en rémission au $6^{\mathrm{e}}$ et au $12^{\mathrm{e}}$ mois.

Conclusion : L'administration de chimiothérapie dans une USI est faisable, mais le processus exige beaucoup de ressources. Les patients atteints d'un cancer hématologique agressif qui ont besoin en urgence d'un traitement constituent le scénario le plus courant. Cette étude souligne la complexité de la gestion et l'importance des équipes de soins multidisciplinaires pour cette population de patients.

Mots-clés : soins intensifs, chimiothérapie, cancer 


\section{INTRODUCTION}

Cancer prevalence is increasing, and new treatments are being developed that are prolonging life and improving the chance of cure. One consequence of this phenomenon is that cancer patients are requiring care in the intensive care unit (ICU) with increasing frequency: for postoperative care after major surgical resection, for chemotherapy- and radiation-related complications, and for concurrent critical illness. ${ }^{1}$ Not only are ICU clinicians encountering more critically ill cancer patients in this setting, but they are being called upon more frequently to administer systemic chemotherapy in the ICU. The literature describing the context, risks, barriers, clinical considerations, and patient outcomes associated with treating cancer in the ICU is sparse..$^{1,2}$

At The Ottawa Hospital, ICU nurses and most other members of the clinical team have no formal training in chemotherapy administration or monitoring. The process of administering chemotherapy in the ICU requires a multidisciplinary approach involving intensivists, hematologists/ oncologists, nurses, and pharmacists. ICU staff use protocols and checklists to coordinate consulting services for cancer management, including writing and checking chemotherapy orders, making dose adjustments for end-organ dysfunction, actually administering the chemotherapy, and disposing of cytotoxic materials. Because ICU nurses are not certified to administer chemotherapy, the current policy requires that a certified oncology nurse come to the ICU to administer the systemic treatment and dispose of cytotoxic materials afterward. Despite this "hands-off" approach, ICU staff are required to anticipate, identify, and manage complications related to both the cancer itself and the cancer treatment.

A search of the literature identified only 4 small studies of chemotherapy administration for the treatment of cancer in the ICU. ${ }^{3-6}$ These studies ranged in size from 37 to 100 patients, with none of them being conducted in North America. ${ }^{3-6}$ The purpose of the current study was to describe the context, complications, and outcomes of administering chemotherapy for cancer-related indications to ICU patients.

\section{METHODS}

This retrospective observational study was conducted at the General Campus of The Ottawa Hospital, an acute tertiary care centre in Ottawa, Ontario. The Ottawa Hospital serves the adult population in the Champlain Local Health Integration Network, which comprises 1.3 million residents in the Ottawa area. Ethics approval for this chart review was received from the Ottawa Health Science Network Research Ethics Board (protocol 20180088-01H).

Consecutive patients admitted to the ICU who received parenteral chemotherapy for treatment of malignancy from
January 1, 2014, to December 31, 2017, were identified from pharmacy records; the pharmacy-generated list was doublechecked via hand searching of written chemotherapy orders. Receipt of systemic chemotherapy in the ICU was confirmed by a review of patients' medical records. Patients were excluded if the systemic chemotherapy was not administered intravenously, if the treatment consisted only of biologic or antibody therapy (e.g., rituximab), or if the treatment was not administered for a cancer indication.

Data were collected from patients' medical records. Baseline characteristics collected included age, sex, and reason for ICU admission (according to Acute Physiology and Chronic Health Evaluation [APACHE] III disease groupings ${ }^{7}$ ). Data collected to describe the indication and types of chemotherapy administered included type of malignancy, chemotherapy regimen and its intent (curative or palliative; scheduled or urgent), cycle of the current regimen, number of previous chemotherapy regimens received for the same indication, regimen modifications, dose adjustments, and prophylaxis received for tumour lysis syndrome (allopurinol or rasburicase). ${ }^{8}$ Hematological malignancies were recorded by grade, where acute myelogenous leukemia, acute lymphoblastic leukemia, and high-grade non-Hodgkin lymphoma were classified as high-grade, and other types of hematological malignancies were classified as low-grade. ${ }^{3,9}$ Solid organ tumours were described as stage I to IV or in terms of local versus extensive disease. Data describing the severity of illness both at ICU admission and at the time of chemotherapy administration included APACHE II scores, ${ }^{10,11}$ RIFLE (risk, injury, failure, loss, endstage renal disease) criteria $^{12}$ (assessed using urine output), need for renal replacement therapy, documented infection (positive culture results up to 1 week before chemotherapy administration and/or receipt of systemic antibiotic or antifungal therapy, excluding prophylaxis with sulfamethoxazoletrimethoprim, acyclovir, or fluconazole and empiric ceftriaxone), Sequential Organ Failure Assessment (SOFA) scores, ${ }^{13}$ white blood cell count, neutrophil count (with neutropenia defined as an absolute neutrophil count less than $1.5 \times 10^{9} / \mathrm{L}$ ), ${ }^{14}$ platelet count (with severe thrombocytopenia defined as platelet count less than $\left.50 \times 10^{9} / \mathrm{L}\right),{ }^{15}$ liver enzymes, bilirubin, and Richmond Agitation-Sedation Scale (RASS) score. ${ }^{16}$ The frequency and severity of chemotherapy-related complications were described by collecting data on the presence of tumour lysis syndrome (identified according to prespecified definition of laboratory and clinical values ${ }^{8}$ ), presence of renal failure 7 days after treatment (using the RIFLE criteria), ${ }^{12}$ and hepatotoxicity 7 days after treatment (defined as an increase in liver enzymes and/or bilirubin to more than 3 times baseline, with baseline values determined from pre-ICU admission bloodwork when available [most patients], and otherwise based on the first measured values from the index hospital admission).${ }^{17}$ Other complications that we considered were 
febrile neutropenia up to 4 weeks after chemotherapy or discharge from hospital, duration of neutropenia, delay of the current chemotherapy cycle, and drug interactions involving the chemotherapy agent. ${ }^{18}$

The outcomes of interest included survival at the time of ICU discharge and hospital discharge, 6- and 12-month survival, and 6- and 12-month remission. Survival and remission were adjudicated by 2 clinicians (F.J.R., M.P.), and disagreements were settled by a third (D.A.). ICU and hospital lengths of stay, as well as duration of mechanical ventilation, were also collected.

Data are presented in tabular format, using measures of central tendency and dispersion, as appropriate, for all patients and also for subgroups of hospital survivors (those who survived to hospital discharge) and hospital nonsurvivors (those who did not survive to hospital discharge). No statistical comparisons between groups were planned or performed.

\section{RESULTS}

Over the 4-year study period, 175 patients were identified as having a prescription for parenteral chemotherapy in the ICU. Of these, 143 patients were excluded (Figure 1). Thirtytwo patients met the inclusion criteria and were included in the analysis $(8,8,5$, and 11 patients in calendar years 2014, 2015,2016 , and 2017, respectively). The demographic characteristics of the patients are presented in Table 1 . The most common reason for ICU admission was respiratory-related $(n=21,66 \%)$, followed by cardiovascular/vascular $(n=3$, $9 \%)$, hematologic $(n=3,9 \%)$, and metabolic $(n=2,6 \%)$. Eighteen patients (56\%) survived to ICU and hospital discharge. All 14 patients who died in hospital died in the ICU. Most patients $(n=27,84 \%)$ had diagnosis of a hematological malignancy for which they received chemotherapy
(Table 2). Most patients had a high-grade hematological malignancy or stage 4 solid tumour malignancy.

The severity of illness at ICU admission and at the time of chemotherapy administration is described in Table 3. All patients were critically ill at ICU admission, with a mean APACHE II score of 20.3 (standard deviation [SD] 9.3). The median duration between ICU admission and chemotherapy administration was 1 day, with a range from 0 to 22 days; therefore, the markers of severity of illness were similar at the time of ICU admission and the time of chemotherapy administration. Organ failure was common in this patient population at the time of ICU admission, with mean SOFA score of 8.8 (SD 4.3) and more than $30 \%$ of patients described as having some degree of renal dysfunction, according to the RIFLE criteria. Patients' critical illness is further supported by the presence of documented infection, with 15 (47\%) of the patients having a documented infection at ICU admission and $16(50 \%)$ at the time of chemotherapy administration, the most common site of infection being the lung. Ten (67\%) of the 15 patients with documented infection at the time of ICU admission did not survive to hospital discharge.

Most patients $(n=29,91 \%)$ received their first cycle of chemotherapy in the ICU, with 23 (72\%) of the regimens having a curative intent (Table 4). We determined that 30 (94\%) of the patients received chemotherapy in an urgent manner. Eight (25\%) of the patients had regimen modifications (most commonly for reduced functional status), whereas 7 (22\%) had dose reductions to accommodate organ dysfunction. The median number of drug interactions involving at least 1 chemotherapeutic agent was 1.5, with a range from 0 to 7 . These drug interactions were identified retrospectively to help describe the complexity of care for patients in this study and had a risk rating of $\mathrm{C}$ (alert to monitor) or $\mathrm{D}$
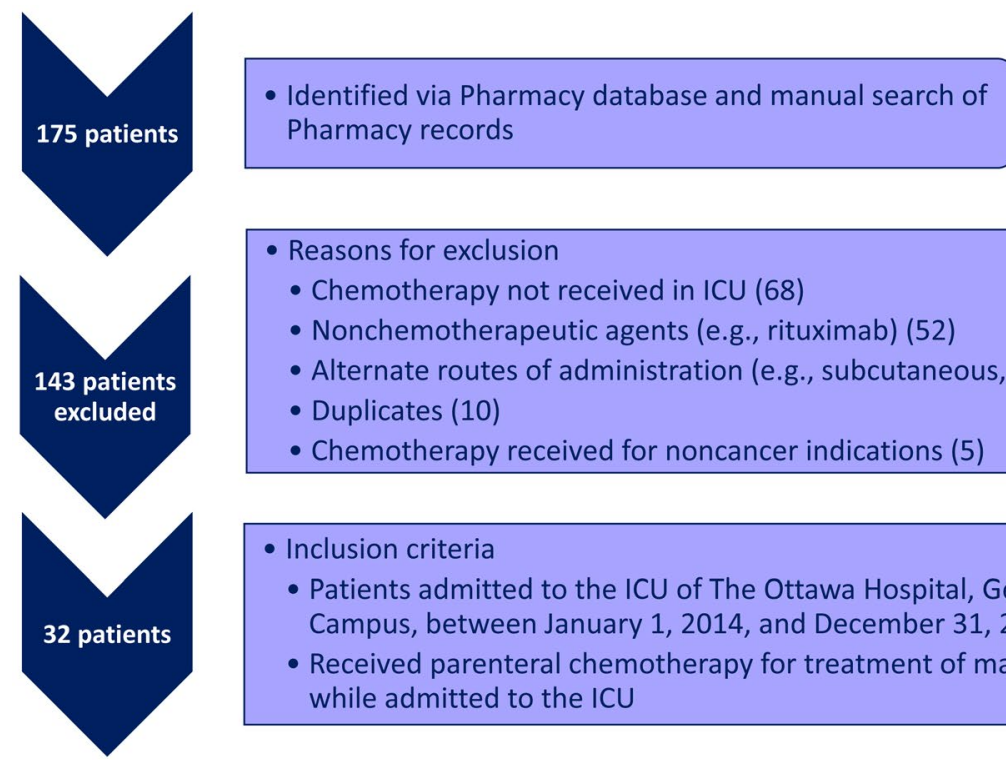

- Reasons for exclusion

- Chemotherapy not received in ICU (68)

- Nonchemotherapeutic agents (e.g., rituximab) (52)

- Alternate routes of administration (e.g., subcutaneous, enteral) (8)

- Duplicates (10)

- Chemotherapy received for noncancer indications (5)

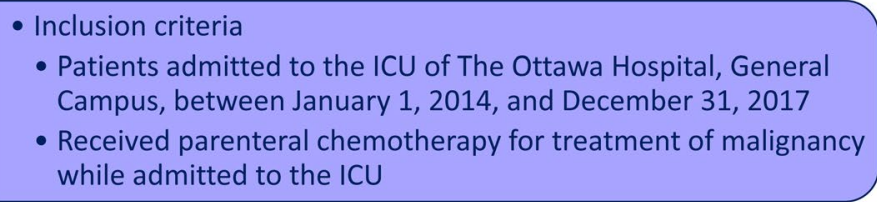

- Patients admitted to the ICU of The Ottawa Hospital, General Campus, between January 1, 2014, and December 31, 2017

- Received parenteral chemotherapy for treatment of malignancy while admitted to the ICU

FIGURE 1. Patient recruitment. ICU = intensive care unit. 
TABLE 1. Demographic Characteristics of Patients

\begin{tabular}{|c|c|c|c|c|c|c|}
\hline \multirow{3}{*}{$\begin{array}{l}\text { Characteristic } \\
\text { Sex, male }\end{array}$} & \multicolumn{6}{|c|}{ Patient Group; No. (\%) of Patients* } \\
\hline & \multicolumn{2}{|c|}{$\begin{array}{c}\text { All } \\
(n=32)\end{array}$} & \multicolumn{2}{|c|}{$\begin{array}{l}\text { Hospital Survivors } \\
\qquad(n=18)\end{array}$} & \multicolumn{2}{|c|}{$\begin{array}{l}\text { Hospital Nonsurvivors } \\
\qquad(n=14)\end{array}$} \\
\hline & 14 & (44) & 10 & $(56)$ & 4 & $(29)$ \\
\hline Age (years) (mean \pm SD) & 55.6 & $=14.5$ & 52.4 & 15.2 & & 13.9 \\
\hline \multicolumn{7}{|l|}{ Reason for ICU admission } \\
\hline Cardiovascular/vascular & 3 & (9) & 1 & (6) & 2 & $(14)$ \\
\hline Respiratory & 21 & $(66)$ & 10 & $(56)$ & 11 & (79) \\
\hline Neurologic & 1 & (3) & 1 & (6) & 0 & $(0)$ \\
\hline Sepsis & 1 & (3) & 1 & (6) & 0 & $(0)$ \\
\hline Metabolic & 2 & (6) & 2 & (11) & 0 & $(0)$ \\
\hline Hematologic & 3 & (9) & 2 & (11) & 1 & (7) \\
\hline Unknown & 1 & (3) & 1 & (6) & 0 & $(0)$ \\
\hline
\end{tabular}

$\mathrm{ICU}=$ intensive care unit, $\mathrm{SD}=$ standard deviation.

*Except where indicated otherwise.

TABLE 2. Types of Cancer

\begin{tabular}{|c|c|c|c|c|c|c|}
\hline \multirow{3}{*}{$\begin{array}{l}\text { Type of Cancer } \\
\text { Hematological }\end{array}$} & \multicolumn{6}{|c|}{ Patient Group; No. (\%) of Patients } \\
\hline & \multicolumn{2}{|c|}{$\begin{array}{c}\text { All } \\
(n=32)\end{array}$} & \multicolumn{2}{|c|}{$\begin{array}{l}\text { Hospital Survivors } \\
\qquad(n=18)\end{array}$} & \multicolumn{2}{|c|}{$\begin{array}{l}\text { Hospital Nonsurvivors } \\
\qquad(n=14)\end{array}$} \\
\hline & 27 & (84) & 15 & $(83)$ & 12 & (86) \\
\hline High-grade malignancy & $22 / 27$ & (81) & 11 & (61) & 11 & (79) \\
\hline Low-grade malignancy & $5 / 27$ & (19) & 4 & (22) & 1 & (7) \\
\hline Acute leukemia & $11 / 27$ & (41) & 4 & (22) & 7 & $(50)$ \\
\hline Lymphoma & $15 / 27$ & (56) & 11 & (61) & 4 & $(29)$ \\
\hline Multiple myeloma & $1 / 27$ & (4) & 0 & $(0)$ & 1 & (7) \\
\hline Solid tumour & 5 & (16) & 3 & (17) & 2 & (14) \\
\hline Small cell carcinoma of lung & $3 / 5$ & (60) & 2 & (11) & 1 & (7) \\
\hline Ovarian cancer & $1 / 5$ & (20) & 0 & $(0)$ & 1 & (7) \\
\hline Non-seminoma, germ cell tumour & $1 / 5$ & (20) & 1 & (6) & 0 & $(0)$ \\
\hline
\end{tabular}

(consider therapy modification).$^{18}$ Patients received a variety of chemotherapy regimens, with most patients receiving a regimen containing 3 or more components.

Twelve-month survival and remission data were available for 28 patients at the time of study completion (Table 5). Outcome data were missing for the other 4 patients because they were lost to follow-up or because there was inadequate documentation for outcome adjudication at 6 and 12 months. Twelve patients (38\%) survived to the 6-month time point and 7 (25\%) survived to 12 months. Among survivors, $47 \%(8 / 17)$ achieved remission at 6 months, and 50\% (7/14) achieved remission at 12 months. Overall, 14 patients $(44 \%)$ in the study population experienced clinical or laboratory tumour lysis syndrome, and 14 patients (44\%) experienced febrile neutropenia.

Numerically, more nonsurvivors had been admitted to the ICU for respiratory failure, and they received deeper sedation, as measured by RASS scores. Nonsurvivors also had more documented infections (mostly lung infections) at the time of chemotherapy administration, relative to hospital survivors. Compared with survivors, nonsurvivors had shorter ICU and hospital lengths of stay but longer duration of mechanical ventilation. Also, fewer nonsurvivors experienced tumour lysis syndrome and hepatotoxicity, but more had renal dysfunction 7 days after receiving their chemotherapy.

\section{DISCUSSION}

Chemotherapy administration in the ICU is a high-risk intervention that requires each member of a large multidisciplinary team to play a key role to ensure that patients receive safe and effective treatment. We sought to describe the context of chemotherapy administration in the ICU for the treatment of malignancy and the outcomes of these patients. In this study, most of the cancer patients who 


\begin{tabular}{|c|c|c|c|c|c|c|}
\hline \multirow[b]{3}{*}{ Severity } & \multicolumn{6}{|c|}{ Patient Group; No. (\%) of Patients* } \\
\hline & \multicolumn{2}{|c|}{ All $(n=32)$} & \multicolumn{2}{|c|}{ Hospital Survivors $(n=18)$} & \multicolumn{2}{|c|}{ Hospital Nonsurvivors $(n=14)$} \\
\hline & $\begin{array}{l}\text { At ICU } \\
\text { Admission }\end{array}$ & $\begin{array}{l}\text { At Chemotherapy } \\
\text { Administration }\end{array}$ & $\begin{array}{c}\text { At ICU } \\
\text { Admission }\end{array}$ & $\begin{array}{l}\text { At Chemotherapy } \\
\text { Administration }\end{array}$ & $\begin{array}{c}\text { At ICU } \\
\text { Admission }\end{array}$ & $\begin{array}{l}\text { At Chemotherapy } \\
\text { Administration }\end{array}$ \\
\hline APACHE II score (mean \pm SD) & $20.3 \pm 9.3$ & $19.5 \pm 8.0$ & $20.4 \pm 9.4$ & $19.4 \pm 8.6$ & $20.1 \pm 7.2$ & $19.6 \pm 7.6$ \\
\hline SOFA score (mean \pm SD) & $8.8 \pm 4.3$ & $8.9 \pm 4.6$ & $9.4 \pm 4.9$ & $9.6 \pm 4.8$ & $8.0 \pm 3.4$ & $8.1 \pm 4.4$ \\
\hline \multicolumn{7}{|l|}{ RIFLE criteria } \\
\hline No dysfunction & $(66)$ & $(69)$ & $(67)$ & (78) & $(64)$ & $(57)$ \\
\hline Risk & $6 \quad(19)$ & (6) & $(22)$ & $(0)$ & $(14)$ & $(14)$ \\
\hline Injury & (3) & (9) & $(0)$ & (6) & $(7)$ & (14) \\
\hline Failure & $(12)$ & $(16)$ & $(11)$ & $(17)$ & $(14)$ & $(14)$ \\
\hline Loss & $(0)$ & $(0)$ & $(0)$ & $(0)$ & $(0)$ & $(0)$ \\
\hline End-stage renal disease & $(0)$ & $(0)$ & $(0)$ & $(0)$ & $(0)$ & $(0)$ \\
\hline Receiving renal replacement therapy & (6) & (9) & $(11)$ & $(17)$ & $(0)$ & $(0)$ \\
\hline Documented infection & $(47)$ & $(50)$ & $(28)$ & (39) & $(71)$ & $9 \quad(64)$ \\
\hline Blood & (6) & (6) & $(0)$ & (6) & $(14)$ & (7) \\
\hline Lung & $(28)$ & $(28)$ & $(17)$ & (11) & $(43)$ & $(50)$ \\
\hline Urine & (9) & (6) & (6) & (6) & $(14)$ & (7) \\
\hline Skin and soft tissue & (3) & (3) & (6) & (6) & $(0)$ & $(0)$ \\
\hline Gastrointestinal & $0 \quad(0)$ & $2 \quad(6)$ & $(0)$ & $(11)$ & $(0)$ & $(0)$ \\
\hline Neutropenia & $6 \quad(19)$ & $8 \quad(25)$ & $4 \quad(22)$ & $5 \quad(28)$ & $2 \quad(14)$ & $3 \quad(21)$ \\
\hline Thrombocytopenia & $13 \quad(41)$ & $14 \quad(44)$ & $8 \quad(44)$ & $8 \quad(44)$ & $5 \quad(36)$ & $(43)$ \\
\hline Liver SOFA score (median and range) & $0 \quad(0$ to 4$)$ & $1 \quad(0$ to 4$)$ & 1 (0 to 4$)$ & $1 \quad(0$ to 4$)$ & $0 \quad(0$ to 3$)$ & $0 \quad(0$ to 4$)$ \\
\hline Renal SOFA score (median and range) & $0 \quad(0$ to 4$)$ & $0 \quad(0$ to 3$)$ & $0 \quad(0$ to 4$)$ & $0 \quad(0$ to 3$)$ & $0 \quad(0$ to 3$)$ & $0.5 \quad(0$ to 3$)$ \\
\hline RASS score (median and range) & $-3 \quad(-5$ to 1$)$ & $-3 \quad(-5$ to 1$)$ & $-1.5 \quad(-5$ to 0$)$ & $-1.5 \quad(-5$ to 0$)$ & $-3 \quad(-5$ to 1$)$ & $-3.5(-5$ to 0$)$ \\
\hline
\end{tabular}

APACHE = Acute Physiology and Chronic Health Evaluation; RASS = Richmond Agitation-Sedation Scale (scores range from -5 [unarousable] to +4 [combative]); RIFLE = risk, injury, failure, loss, end-stage renal disease; SD = standard deviation; SOFA= Sequential Organ Failure Assessment (scores range from 0 to 4 , where higher numbers indicate greater organ dysfunction).

*Except where indicated otherwise.

received chemotherapy in the ICU had a hematological malignancy. For a large number of patients, this was their first treatment, and it was required on an urgent basis because of high severity of illness and/or extent of disease. Few patients had significant renal or hepatic dysfunction; however, one-quarter of patients required dose reductions, and one-quarter required modifications of treatment regimens. The patients' severity of illness was high, both at admission and at the time of chemotherapy administration. Half of the patients had a documented infection that was being treated at the time of chemotherapy administration. Overall, survival rates in this study were in keeping with previously reported survival rates for patients with aggressive hematological malignancies. ${ }^{19}$

Although a formal comparison of survivors and nonsurvivors was beyond the scope of this study, it is interesting to note that, at least numerically, nonsurvivors were more likely to receive chemotherapy in the ICU for palliative intent, were more likely to have active infections at the time of chemotherapy administration, were less likely to experience tumour lysis syndrome, and ultimately had shorter hospital and ICU stays but longer duration of mechanical ventilation when compared with survivors. While these all appear to be logical observations, more nonsurvivors than survivors experienced some degree of renal dysfunction but less hepatotoxicity after chemotherapy, which is more difficult to explain. The observation that active infection was more often present in nonsurvivors at the time of chemotherapy administration may represent an opportunity for quality improvement initiatives, with acknowledgement that balancing the risks of delaying urgent treatment for the underlying malignancy likely also has consequences. However, in cases where delaying chemotherapy by a week or two is possible, it may be an approach worth considering, to allow completion of treatment of concomitant infections. Given the limitations associated with our sample size, we 


\begin{tabular}{|c|c|c|c|c|c|c|}
\hline \multirow{3}{*}{$\begin{array}{l}\text { Characteristic } \\
\text { Time from ICU admission to chemotherapy administration (days) } \\
\text { (median and range) }\end{array}$} & \multicolumn{6}{|c|}{ Patient Group; No. (\%) of Patients* } \\
\hline & \multicolumn{2}{|c|}{$\begin{array}{c}\text { All } \\
(n=32)\end{array}$} & \multicolumn{2}{|c|}{$\begin{array}{l}\text { Hospital Survivors } \\
\qquad(n=18)\end{array}$} & \multicolumn{2}{|c|}{$\begin{array}{l}\text { Hospital Nonsurvivors } \\
\qquad(n=14)\end{array}$} \\
\hline & 1 & $(0-22)$ & 2 & $(0-22)$ & 0 & $(0-12)$ \\
\hline First cycle of chemotherapy given in the ICU & 29 & $(91)$ & 18 & $(100)$ & 11 & (79) \\
\hline \multicolumn{7}{|l|}{ Intent of chemotherapy } \\
\hline Palliative & 9 & $(28)$ & 4 & $(22)$ & 5 & (36) \\
\hline Curative & 23 & $(72)$ & 14 & (78) & 9 & (64) \\
\hline \multicolumn{7}{|l|}{ Intent of cycle } \\
\hline Scheduled & 2 & (6) & 0 & $(0)$ & 2 & (14) \\
\hline Urgent & 30 & $(94)$ & 18 & $(100)$ & 12 & $(86)$ \\
\hline $\begin{array}{l}\text { Received previous chemotherapy regimens } \\
\text { for same malignancy }\end{array}$ & 3 & (9) & 2 & (11) & 1 & (7) \\
\hline Regimen modification & 8 & $(25)$ & 5 & $(28)$ & 3 & $(21)$ \\
\hline Dose reduction & 7 & $(22)$ & 4 & $(22)$ & 3 & $(21)$ \\
\hline Drug interactions ${ }^{\dagger}$ per patient (median and range) & 1.5 & $(0-7)$ & 1 & $(0-7)$ & 2 & $(0-7)$ \\
\hline C-level interactions (median and range) & 1 & $(0-5)$ & 1 & $(0-5)$ & 2 & $(0-5)$ \\
\hline D-level interactions (median and range) & 0 & $(0-3)$ & 0 & $(0-2)$ & 0 & $(0-3)$ \\
\hline Use of G-CSF & 12 & (38) & 5 & $(28)$ & 7 & $(50)$ \\
\hline Use of TLS prophylaxis & 25 & (78) & 15 & $(83)$ & 10 & (71) \\
\hline \multicolumn{7}{|l|}{ Chemotherapy regimen } \\
\hline CHOP $\pm \mathrm{R}$, CHOP modified & 11 & (34) & 7 & (39) & 4 & (29) \\
\hline Carboplatin-containing regimens: CarboEtop, CarboTaxol & 3 & (9) & 1 & (6) & 2 & $(14)$ \\
\hline Single agent: HD MTX, cytarabine, doxorubicin, vincristine & 5 & $(16)$ & 2 & $(11)$ & 3 & $(21)$ \\
\hline Leukemia (re)induction: IDAC, MEC & 4 & $(13)$ & 1 & (6) & 3 & $(21)$ \\
\hline CVAD A/1 & 2 & (6) & 1 & (6) & 1 & $(7)$ \\
\hline$C V P \pm R$ & 4 & $(13)$ & 4 & $(22)$ & 0 & $(0)$ \\
\hline Other: BEP (3 days), VD PACE, Cis75Etop & 3 & (9) & 2 & $(11)$ & 1 & (7) \\
\hline
\end{tabular}

$\mathrm{BEP}=$ bleomycin + etoposide + cisplatin; CarboEtop = carboplatin + etoposide; CarboTaxol = carboplatin + paclitaxel; $\mathrm{CHOP} \pm \mathrm{R}=$ cyclophosphamide + doxorubicin + vincristine + prednisone \pm rituximab; Cis75Etop = cisplatin + etoposide; CVAD = cyclophosphamide + vincristine + doxorubicin + dexamethasone; $\mathrm{CVP} \pm \mathrm{R}=$ cyclophosphamide + vincristine + prednisone \pm rituximab; $\mathrm{G}$-CSF = granulocyte colony-stimulating factor; HD MTX = high-dose methotrexate; ICU = intensive care unit; IDAC = idarubicin + cytarabine; MEC = mitoxantrone + etoposide + cytarabine; TLS = tumour lysis syndrome; VD PACE = bortezomib + dexamethasone + platinum agent + doxorubicin + cyclophosphamide + etoposide.

*Except where indicated otherwise.

${ }^{\dagger} \mathrm{C}$-level interactions = alert to monitor; D-level interactions = consider therapy modification.

caution against the over-interpretation of these comparisons but would suggest that future investigations explore some of these associations.

Care requirements were also complex in this patient population, given the frequency of end-organ dysfunction requiring dose modifications, drug interactions, and adverse events. Most patients received chemotherapy regimens involving 3 or more drugs, which is associated with a higher resource burden in most cases. For example, for a patient receiving the regimen $\mathrm{CHOP}$ (cyclophosphamide, doxorubicin, vincristine, prednisone), a certified nurse must be present to administer 3 IV medications, which can take upwards of an hour.
Three other retrospective observational studies have been conducted in similar fashion. One study, completed by Benoit and others, ${ }^{3}$ involved patients with hematological malignancies who received (or were intended to receive) chemotherapy in the ICU. The size of their study sample was comparable to ours, at 37 patients. They found that only ventilation during the ICU stay was associated with in-hospital mortality among patients who received chemotherapy. Our study findings were comparable to theirs, with the majority of patients in both studies having high-grade hematological malignancies, similar numbers of patients having active infection at the time of chemotherapy administration, and similar rates of in-hospital mortality. Song 
Patient Group; No. (\%) of Patients*

\begin{tabular}{|c|c|c|c|c|c|c|}
\hline \multirow{2}{*}{$\begin{array}{l}\text { Outcome } \\
\text { Length of ICU admission (days) (median and range) }\end{array}$} & \multicolumn{2}{|c|}{$\begin{array}{c}\text { All } \\
(n=32)\end{array}$} & \multicolumn{2}{|c|}{$\begin{array}{l}\text { Hospital Survivors } \\
\qquad(n=18)\end{array}$} & \multicolumn{2}{|c|}{$\begin{array}{l}\text { Hospital Nonsurvivors } \\
\qquad(n=14)\end{array}$} \\
\hline & 9.5 & $(3-47)$ & 10.5 & $(4-47)$ & 8 & $(3-37)$ \\
\hline Length of hospital admission (days) (median and range) & 23.5 & $(6-342)$ & 28 & $(9-342)$ & 16.5 & $(6-95)$ \\
\hline \multicolumn{7}{|l|}{ Survival } \\
\hline At ICU discharge & 18 & $(56)$ & 18 & $(100)$ & 0 & $(0)$ \\
\hline At 6 months & 12 & $(38)$ & 12 & $(67)$ & 0 & $(0)$ \\
\hline At 12 months $^{\dagger}$ & $7 / 28$ & $(25)$ & $7 / 14$ & $(50)$ & 0 & (0) \\
\hline \multicolumn{7}{|l|}{ Remission } \\
\hline At 6 months ${ }^{\dagger}$ & $8 / 31$ & $(26)$ & $8 / 17$ & $(47)$ & 0 & $(0)$ \\
\hline At 12 months $^{\dagger}$ & $7 / 28$ & $(25)$ & $7 / 14$ & $(50)$ & 0 & (0) \\
\hline Length of mechanical ventilation (days) (median and range) & 5 & $(0-35)$ & 4.5 & $(0-35)$ & 7.5 & $(0-34)$ \\
\hline \multicolumn{7}{|l|}{ Tumour lysis syndrome } \\
\hline Laboratory & 7 & $(22)$ & 5 & $(28)$ & 2 & $(14)$ \\
\hline Clinical & 7 & $(22)$ & 5 & $(28)$ & 2 & $(14)$ \\
\hline \multicolumn{7}{|l|}{ RIFLE criteria, 7 days after treatment } \\
\hline No dysfunction & 24 & $(75)$ & 15 & (83) & 9 & (64) \\
\hline Risk & 2 & (6) & 2 & $(11)$ & 0 & $(0)$ \\
\hline Injury & 3 & (9) & 0 & $(0)$ & 3 & $(21)$ \\
\hline Failure & 3 & (9) & 1 & (6) & 2 & (14) \\
\hline Loss & 0 & $(0)$ & 0 & $(0)$ & 0 & $(0)$ \\
\hline End-stage renal disease & 0 & (0) & 0 & (0) & 0 & $(0)$ \\
\hline Hepatotoxicity, 7 days after treatment & 3 & (9) & 3 & (17) & 0 & $(0)$ \\
\hline \multicolumn{7}{|l|}{ Febrile neutropenia after chemotherapy } \\
\hline Present & 14 & (44) & 8 & (44) & 6 & (43) \\
\hline Duration (days) (median and range) & 2 & $(0-16)$ & 3.5 & $(0-14)$ & 2 & $(0-16)$ \\
\hline
\end{tabular}

ICU = intensive care unit; RIFLE = risk, injury, failure, loss, end-stage renal disease.

*Except where indicated otherwise.

${ }^{\dagger}$ Denominator indicates the number of patients for whom data were available at the specified time point.

and others ${ }^{5}$ conducted another study in patients with hematological or solid tumour malignancies who received chemotherapy in the ICU. The degree of organ failure and the occurrence of respiratory failure requiring mechanical ventilation were both independent predictors of mortality in this study, whereas degree of organ involvement, disease status, and extent of underlying malignancy were not shown to have an impact on mortality. Similar to our study, the majority of patients had diagnosis of a hematological malignancy and were being treated for their first presentation of disease, and the time to onset of treatment and ICU mortality rate were the same. The final study with a study design similar to that of the current study was conducted by Wohlfarth and others. ${ }^{6}$ Their retrospective observational study included 56 patients with hematological or solid tumor malignancies, among whom survival was associated with independent factors of age, comorbidity, severity of acute illness, septic shock, vasopressor use, and renal replacement therapy. The rate of hospital survival, the frequency of hematological malignancies, and the reason for admission to the ICU were similar to the current study, but the overall rate of tumour lysis syndrome was lower.

Administering chemotherapy in the ICU adds complexity to an already complex environment. Because ICU nurses are not certified to administer chemotherapy, a nurse from the oncology unit, with appropriate certification, must be available to administer the drugs. Given that most patients received 3 or more agents in their regimen, there can be many issues with staffing and coordination of care. Upwards of 15 health care professionals may be involved in the many steps of this process, which not only creates a more complex task but also adds logistical and safety issues. The hematologist/oncologist, in consultation with the ICU clinical team, is often responsible for making the decision to treat the patient and is also responsible for writing the chemotherapy order. Pharmacists from both hematology/oncology and critical care review the written order for accuracy and make dose modifications 
for end-organ dysfunction as required. They also coordinate the logistical processes related to scheduling times of administration and preparation of the medication by pharmacy technicians, taking into account the fact that some drugs have a very short period of stability. Nursing staff are heavily involved throughout the entire process. The ICU nurse is responsible for ensuring that all parties are notified that an order has been written, while care facilitators and clinical care leaders from both the ICU and oncology/ hematology coordinate the availability of a certified nurse who can come to the ICU to administer the chemotherapy. This nurse, along with the pharmacist, educates the bedside nurses about monitoring for adverse events and administration of complementary therapies (e.g., antinauseants, hydration). The ICU medical team is still primarily responsible for the patient's overall care, including monitoring for adverse events and treatment outcomes. Because this process involves many people and tasks, algorithms and checklists are used to minimize errors and ensure the process unfolds as efficiently as possible. One consideration to minimize the number of participants in a patient's circle of care would be to maintain a limited number of chemotherapy-trained ICU nurses. The challenge would then be to ensure that these specialized ICU nurses are available for patients needing to receive chemotherapy and to have a contingency plan for when they are not available. There would also be concerns about maintaining skills, given that chemotherapy administration in the ICU is relatively infrequent.

We identified and made efforts to mitigate the limitations associated with this study. Because of the retrospective nature of the study design, data collection was limited by documentation and what was available in the electronic record; however, we encountered less than $1 \%$ missing data. We relied on a pharmacy database to generate the list of patients who met the inclusion criteria. To minimize the risk of missing eligible patients and ensure completeness of our sample, we further verified the patient list by hand-sorting through all written chemotherapy orders for the study period. Given the nature of select data points that were collected and the possibility of interpretation, we developed an adjudication process, whereby 3 clinical experts who were members of the patients' care circles and who had access to alternative forms of information helped to determine select outcomes. Another limitation relates to generalizability to a larger population, given that the study was conducted in a single-centre ICU; however, we can confirm that this was the only ICU to administer chemotherapy in the Champlain LHIN. Therefore, any patients treated through The Ottawa Hospital and included in this study would not have received chemotherapy in the ICU of any other hospital (if they had, such treatment could potentially have affected their outcomes). Given the small number of patients in this study, we were unable to make any statements about predictors of mortality; however, the results do provide an idea of issues that may be experienced with patients admitted to the ICU. Finally, this cohort of patients represents only a subset of the patients who receive chemotherapeutic agents in the ICU; other ICU patients may receive biologic agents such as rituximab for a variety of indications, may receive chemotherapy via different routes (e.g., enteral, subcutaneous), or may receive chemotherapy for noncancer indications (e.g., cyclophosphamide for vasculitis). The procedures and policies described in this paper apply only to patients in the ICU receiving IV chemotherapy for cancer indications. In all other scenarios, the processes of drug prescription, delivery, administration, and monitoring are less well defined.

\section{CONCLUSION}

In this retrospective observational study, administration of chemotherapy in the ICU was most commonly employed for treatment for hematological malignancies; a variety of regimens were used. Severity of illness was both evident and similar at the time of ICU admission and the time of chemotherapy administration. In this study population, complexity of care was high because of end-organ dysfunction, drug interactions, and concomitant critical illness, including high rates of active infection. Chemotherapy-related adverse events and mortality were high. This study highlights the complexity of managing care for these patients and the importance of multidisciplinary care teams.

\section{References}

1. Kostakou E, Rovina N, Kyriakopoulou M, Koulouris NG, Koutsoukou A. Critically ill cancer patient in intensive care unit: issues that arise. J Crit Care. 2014;29(5):817-22.

2. Moors I, Pene F, Lengline É, Benoit D. Urgent chemotherapy in hematological patients in the ICU. Curr Opin Crit Care. 2015;21(6):559-68.

3. Benoit DD, Depuydt PO, Vandewoude KH, Offner FC, Boterberg T, De Cock CA, et al. Outcome in severely ill patients with hematological malignancies who received intravenous chemotherapy in the intensive care unit. Intensive Care Med. 2006;32(1):93-9.

4. Darmon M, Thiery G, Ciroldi M, de Miranda S, Galicier L, Raffoux E, et al. Intensive care in patients with newly diagnosed malignancies and a need for cancer chemotherapy. Crit Care Med. 2005;33(11):2488-93.

5. Song JU, Suh GY, Chung MP, Kim H, Kwon OJ, Jung CW, et al. Risk factors to predict outcome in critically ill cancer patients receiving chemotherapy in the intensive care unit. Support Care Cancer. 2011;19(4):491-5.

6. Wohlfarth P, Staudinger T, Sperr WR, Bojic A, Robak O, Hermann A, et al. Prognostic factors, long-term survival, and outcome of cancer patients receiving chemotherapy in the intensive care unit. Ann Hematol. 2014;93(10):1629-36.

7. Knaus WA, Wagner DP, Draper EA, Zimmerman JE, Bergner M, Bastos PG, et al. The APACHE III prognostic system. Risk prediction of hospital mortality for critically ill hospitalized adults. Chest. 1991;100(6):1619-36.

8. Howard SC, Jones DP, Pui CH. The tumor lysis syndrome. N Engl J Med. 2011;364(19):1844-54.

9. Vandijck DM, Benoit DD, Depuydt PO, Offner FC, Blot SI, Van Tilborgh $\mathrm{AK}$, et al. Impact of recent intravenous chemotherapy on outcome in severe sepsis and septic shock patients with hematological malignancies. Intensive Care Med. 2008;34(5):847-55. 
10. Knaus WA, Draper EA, Wagner DP, Zimmerman JE. APACHE II: a severity of disease classification system. Crit Care Med. 1985;13(10):818-29.

11. Soares M, Fontes F, Dantas J, Gadelha D, Cariello P, Nardes F, et al. Performance of six severity-of-illness scores in cancer patients requiring admission to the intensive care unit: a prospective observational study. Crit Care. 2004;8(4):R194-203.

12. Lopes JA, Jorge S. The RIFLE and AKIN classifications for acute kidney injury: a critical and comprehensive review. Clin Kidney J. 2013;6(1):8-14.

13. Ferreira FL, Bota DP, Bross A, Mélot C, Vincent JL. Serial evaluation of the SOFA score to predict outcome in critically ill patients. JAMA. 2001;286(14):1754-8.

14. Boxer LA. How to approach neutropenia. Hematology Am Soc Hematol Educ Program. 2012;2012:174-82.

15. Williamson DR, Albert M, Heels-Ansdell D, Arnold DM, Lauzier F, Zarychanski R, et al. Thrombocytopenia in critically ill patients receiving thromboprophylaxis: frequency, risk factors, and outcomes. Chest. 2013;144(4):1207-15.

16. Sessler CN, Gosnell MS, Grap MJ, Brophy GM, O’Neal PV, Keane $\mathrm{KA}$, et al. The Richmond Agitation-Sedation Scale: validity and reliability in adult intensive care unit patients. Am J Resp Crit Care Med. 2002;166(10):1338-44.

17. Grigorian A, O'Brien CB. Hepatotoxicity secondary to chemotherapy. J Clin Transl Hepatol. 2014;2(2):95-102.

18. Common terminology criteria for adverse events (CTCAE). Version 4.03. Department of Health and Human Services (US); 2010.

19. Canadian Cancer Statistics Advisory Committee. Canadian cancer statistics 2019. Canadian Cancer Society; 2019 [cited 2020 Jan 28]. Available from: cancer.ca/Canadian-Cancer-Statistics-2019-EN
Salmaan Kanji, PharmD, is with The Ottawa Hospital and the Ottawa Hospital Research Institute, Ottawa, Ontario.

Erica MacLean, BScPharm, is with The Ottawa Hospital, Ottawa, Ontario. Farah Joy Rashid, BScPharm, is with The Ottawa Hospital, Ottawa, Ontario. Michelle Pittman, BSCPharm, is with The Ottawa Hospital, Ottawa, Ontario. Melanie Trinacty, BScPharm, is with The Ottawa Hospital, Ottawa, Ontario. David Allan, MD, FRCPC, is with The Ottawa Hospital and the Ottawa Hospital Research Institute, Ottawa, Ontario.

Erin Rosenberg, MD, MHA, FRCPC, is with The Ottawa Hospital, Ottawa, Ontario. This work was done on behalf of the Resource Optimization Network (www.resourceoptimizationnetwork.com). Salmaan Kanji and Erica Maclean contributed equally to all aspects of this study and are co-primary authors on this article.

Competing interests: Melanie Trinacty has received personal fees from Teva Pharmaceuticals for activities outside the work reported here. No other competing interests were declared.

Address correspondence to:

Dr Salmaan Kanji

The Ottawa Hospital and Ottawa Hospital Research Institute

501 Smyth Road

Ottawa ON K1H 8L6

e-mail: skanji@toh.ca

Funding: This study was funded by a research grant from the Department of Critical Care, The Ottawa Hospital.

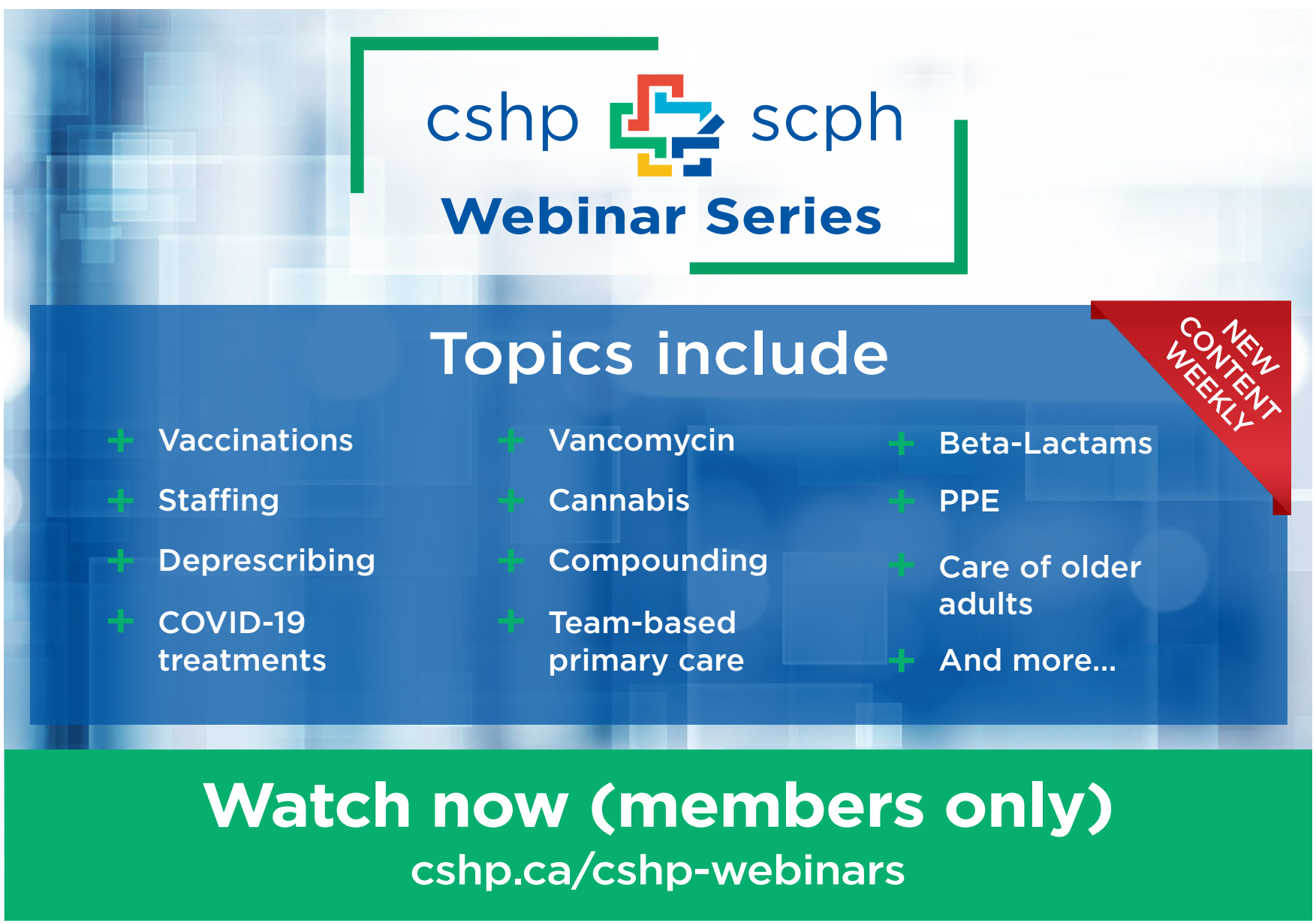

